CLINICAL STUDY

\title{
Unacylated ghrelin is associated with changes in body composition and body fat distribution during long-term exercise intervention
}

\author{
Henna Cederberg $^{1}$, Ulla Rajala ${ }^{1}$, Vesa-Matti Koivisto ${ }^{1}$, Jari Jokelainen ${ }^{1,2}$, Heljä-Marja Surcel ${ }^{3}$, \\ Sirkka Keinänen-Kiukaanniemi ${ }^{1,2,4}$ and Markku Laakso ${ }^{5}$ \\ ${ }^{1}$ Faculty of Medicine, Institute of Health Sciences, University of Oulu, PO Box 5000, FIN-90014 Oulu, Finland, ${ }^{2}$ Unit of General Practice, Oulu \\ University Hospital, Oulu, Finland, ${ }^{3}$ Institute for National Health and Welfare (THL), Oulu, Finland, ${ }^{4}$ Oulu Health Center, Diabetes Unit, Saaristonkatu, \\ Oulu, Finland and ${ }^{5}$ Department of Medicine, University of Eastern Finland and Kuopio University Hospital, Kuopio, Finland \\ (Correspondence should be addressed to H Cederberg; Email: henna.cederberg@oulu.fi)
}

\begin{abstract}
Objective: Ghrelin, a gut-brain peptide involved in energy homeostasis, circulates predominantly $(>90 \%)$ in unacylated form. Previous studies, however, have focused on total and acylated ghrelin, and the role of unacylated ghrelin (UAG) is not well understood. Particularly, the association of UAG with weight loss and changes in body composition in adults remains unclear. We hypothesized that exercise-associated increase in UAG level is associated with weight loss, favorable changes in body composition, and body fat distribution.

Design and methods: A prospective study of 552 young men (mean age 19.3 and range 19-28 years) undergoing military service with structured 6-month exercise training program. Exercise performance, body composition, and biochemical measurements were obtained at baseline and follow-up. Association between changes in UAG levels and body composition and body fat distribution were evaluated.

Results: An increase in UAG level during the exercise intervention was associated with reduced weight, fat mass (FM), fat percentage (fat \%), and waist circumference, but not with fat-free mass. Inverse associations of changes in UAG level with changes in waist circumference and fat \% were independent of weight at baseline, and changes in weight and exercise performance. Associations of changes in UAG level with waist circumference were significantly stronger than with fat \% after the adjustment for confounding variables.

Conclusion: UAG is associated with changes in body weight and body composition during an intensive long-term exercise intervention in young men. The association of UAG levels with changes in central obesity was stronger than with total FM.
\end{abstract}

European Journal of Endocrinology $165243-248$

\section{Introduction}

Ghrelin, a 28-amino acid gut-brain peptide regulates a wide range of physiological functions, including energy homeostasis, body weight, food intake, and glucose metabolism $(1,2)$. Low levels of total ghrelin are associated with obesity, metabolic syndrome, and insulin resistance (2). Circulating ghrelin is present in two different forms: unacylated ghrelin (UAG, $>90 \%$ of total ghrelin) and acylated ghrelin (AG) (1). The majority of functions of ghrelin has been attributed to total and AG ghrelin, the latter being an agonist of the GH secretagogue receptor $\left(G_{H S}-R_{1 a}\right)$ (1). UAG, originally considered a non-functional peptide, has also subsequently proven to be active (3). The physiological role of UAG, however, remains uncertain.

Emerging evidence suggests that AG and UAG exert different physiological effects on appetite control and glucose metabolism (4-7). AG has been reported to stimulate food intake, whereas UAG does not seem to have an orexigenic effect (7). AG is associated with reduced insulin sensitivity, whereas co-administration of UAG with AG seems to improve insulin sensitivity $(5,8)$. Whether AG and UAG also have different roles in body weight, body composition, and adiposity remains unclear.

Increased exercise in children has been shown to induce a non-significant increase in the level of UAG, in contrast to unchanged AG (9). Increased levels of total ghrelin have been reported with long-term physical activity in adults in some $(10,11)$, but not in all, studies $(12,13)$. The relationship between the level of UAG and exercise in adults and the subsequent regulatory role of changes in UAG on changes in body composition and body fat distribution are unclear. We hypothesized that i) exercise-associated increase in the level of UAG is 
associated with weight loss and favorable changes in body composition, and that ii) UAG is associated with favorable changes in body fat distribution in response to an exercise intervention. Thus the aim of this study was to evaluate changes in the level of UAG, body composition, and the association of UAG with body fat distribution in 552 young men undergoing an intensive 6-month exercise program.

\section{Methods}

\section{Research design}

A prospective study with an intensive exercise intervention design and 6-month follow-up was performed on men (mean age of 19.3 years, s.D. 1.0, and range 18-28 years) entering military service at the Sodankylä Jaeger Brigade, Finland, as described in detail elsewhere (14). Of these, 58\% served for 6 months (privates) and were included in this study. Paired UAG measurements from baseline and follow-up were available for 552 men. All participants gave a written consent to use the collected data for scientific purposes. The study protocol was approved by the Ethics Committee of Lapland Central Hospital, Rovaniemi, Finland.

\section{Study protocol}

Data were collected at the entry and at the end of military service, as described in detail elsewhere (14). The follow-up period was 6 months. Anthropometrics, body composition, and exercise performance measurements were taken, and venous blood samples were collected at baseline and follow-up. Weight (to nearest $0.1 \mathrm{~kg}$ ) in light clothing and height (to nearest $0.5 \mathrm{~cm}$ ) were measured. Waist circumference $(\mathrm{cm})$ was measured at midway between the lowest rib and the iliac crest. Body mass index (BMI) was calculated dividing body weight $(\mathrm{kg})$ by the square of the height $\left(\mathrm{m}^{2}\right)$. Body composition was analyzed by multifrequency bioelecric impedance analysis (BIA; InBody 720 , Biospace, Seoul, Korea), as described previously in detail (14). The following body composition indices were derived and used in this analysis: fat percentage (fat \%), fat mass (FM, kg), fat-free mass (FFM, $\mathrm{kg}$ ), and visceral fat area (VFA, $\mathrm{cm}^{2}$ ).

Biochemical measurements Venous blood samples were drawn after $12 \mathrm{~h}$ of overnight fasting. Plasma concentration of UAG was determined using commercially available enzyme immunoassay Kit, from SPI-BIO, Bertin Technologies (Montigny-le-Bretonneux, France). The lower limit of detection for the UAG assay was $2 \mathrm{pg} / \mathrm{ml}$, and intra- and inter-assay coefficients of variation were 11.8 and $13.2 \%$ respectively.

\section{Exercise performance}

Aerobic performance Aerobic performance was measured by the Cooper 12 min running test (15), as described in detail elsewhere (14). Participants were instructed to run 12 min with a maximal effort, and the test result was reported by the distance run with $10 \mathrm{~m}$ accuracy. The Cooper $12 \mathrm{~min}$ running test was developed for military use, and it provides a fairly good estimation for maximal oxygen uptake $\left(\mathrm{VO}_{2 \max }\right)$ without treadmill testing, which is considered as a 'gold standard' (correlation coefficients are 0.84-0.92 with the treadmill $\left.\mathrm{VO}_{2 \max }\right)(15,16)$.

Muscle fitness Muscle fitness was measured by five tests: sit-ups, a back-muscle test (testing endurance of abdominal, back, and hip-flexor muscles), push and pull-ups (testing upper extremities), and standing long jump (testing explosive muscle strength), as described in detail elsewhere $(14,17)$. Participants were asked to perform the maximum possible number of repetitions of concentric muscle actions in $60 \mathrm{~s}$. Results were recorded to the accuracy of the nearest repetition, and for the long jump, to the nearest $1 \mathrm{~cm}$. Muscle fitness performance was graded for each component $(0$, poor; 1, satisfactory; 2, good; 3, very good), and a sum of scores of individual components was calculated to determine the total muscle fitness index (MFI; 0-4, poor; 5-8, satisfactory; 9-12, good; 13-15, very good).

\section{Amount of physical exercise}

Physical activity during military training consists of exercise training (includes running, nordic walking, strength training, martial arts, orienteering, swimming, cross-country skiing, and recovery training), as well as combat training and marching. The estimated amount of physical activity during the 8-week basic training period in the beginning of the military service corresponds on average to $\sim 4 \mathrm{~h}$ of sports-related physical activity (running, nordic walking, and strength training) and $12 \mathrm{~h}$ of military-related physical training (combat training and marching) per week. After the basic training period, the total amount of physical activity varies slightly during subsequent special training and unit training periods, and also depending on the branch of service.

\section{Statistical analysis}

Continuous variables are presented as mean \pm s.D. or median and interquartile range. Paired $t$-test was used to evaluate the difference between the mean values at baseline and follow-up. Weight loss of $2.5 \%$ or greater has been previously shown to be clinically significant (18). Therefore, weight change was divided into three groups of weight loss $\geq 2.5 \%(n=166)$, stable weight $(n=155)$, and weight gain $\geq 2.5 \%(n=143)$. ANOVA 
Table 1 Characteristics of the participants at baseline and their changes during the 6-month follow-up. Values are mean (s.D.), except for unacylated ghrelin (median and interquartile range).

\begin{tabular}{|c|c|c|c|}
\hline Variable & At baseline & $\begin{array}{c}\text { Change } \\
\text { during } \\
\text { 6-month } \\
\text { follow-up }\end{array}$ & $P$ value \\
\hline Age (years) & $19.3(0.9)$ & & \\
\hline Weight (kg) & $75.1(14.9)$ & $-1.3(5.5)$ & $<0.001$ \\
\hline $\begin{array}{l}\text { Body mass } \\
\text { index }\left(\mathrm{kg} / \mathrm{m}^{2}\right)\end{array}$ & $24.2(4.3)$ & $-0.6(1.8)$ & $<0.001$ \\
\hline $\begin{array}{l}\text { Waist circumference } \\
\text { (cm) }\end{array}$ & $81.9(11.1)$ & $-0.6(6.1)$ & 0.034 \\
\hline Fat mass $(\mathrm{kg})$ & $14.1(9.7)$ & $-2.1(5.0)$ & $<0.001$ \\
\hline Body fat (\%) & $17.5(8.6)$ & $-1.8(4.9)$ & $<0.001$ \\
\hline Visceral fat area $\left(\mathrm{cm}^{2}\right)$ & $70.2(53.3)$ & $-34.7(32.5)$ & $<0.001$ \\
\hline Fat-free mass $(\mathrm{kg})$ & $61.0(7.3)$ & $-0.8(2.7)$ & $<0.001$ \\
\hline $\begin{array}{l}12 \text { min running } \\
\text { test }(\mathrm{m})\end{array}$ & 2395 (434) & 221 (352) & $<0.001$ \\
\hline $\begin{array}{l}\text { Muscle fitness index } \\
\text { (points) }\end{array}$ & $7.3(3.9)$ & $1.5(2.4)$ & $<0.001$ \\
\hline $\begin{array}{l}\text { Unacylated ghrelin } \\
(\mathrm{pg} / \mathrm{ml})\end{array}$ & $32.6(13.5-59.4)$ & $13.5(44.5)$ & $<0.001$ \\
\hline
\end{tabular}

$P$ values are from the paired $t$-test.

was used to compare the differences in variables between the groups. Log transformation was performed for the levels of UAG at baseline because of skewed distribution of UAG. Associations between dependent variables and UAG level and the changes in these variables were assessed by Spearman's correlation coefficients. Univariate linear regression analysis was used to estimate the association of a change in UAG level with changes in waist circumference and fat \% (model 1). Multivariate linear regression analysis was used to estimate the association of a change in UAG level with changes in waist circumference and fat \%, adjusted for weight at baseline (model 2), weight at baseline and weight change (model 3), weight at baseline and change in MFI (model 4), and weight at baseline, weight change, and change in MFI (model 5). $P<0.05$ was considered as statistically significant. Statistical analysis was performed using SPSS Statistics 18 for Windows, SPSS, Inc., Chigago, IL, USA and SAS 9.1.3. for Windows, SAS Institute, Inc., Gary, NC, USA).

\section{Results}

\section{Changes in anthropometry, body composition, and exercise performance}

Characteristics of the participants at baseline are described in Table 1. Median concentration of UAG at baseline was $32.6 \mathrm{pg} / \mathrm{ml}$ (interquartile range 13.5-59.4), and its mean change during exercise intervention was $13.5 \mathrm{pg} / \mathrm{ml}$ (s.D. 44.5). Weight, waist circumference, FM, fat \%, and VFA all decreased during the intervention, while FFM increased $(P<0.001$ for all). Both endurance performance in the 12 min running test (mean increase of $221 \mathrm{~m}$, s.D. 352) and strength performance (mean increase of 1.5 points, S.D. 2.4 in MFI) improved during the follow-up ( $P<0.001$ for both).

\section{Comparison of the weight loss and the non-weight loss groups}

Participants with weight loss of $2.5 \%$ or greater during the follow-up had significantly lower levels of UAG at baseline compared with the other groups $(P<0.001$; Table 2). The weight loss group (weight loss $\geq 2.5 \%$ ) had a significantly greater increase in the UAG level $(19.12 \mathrm{pg} / \mathrm{ml})$ than the weight stable and weight gaining groups (13.64 and $2.85 \mathrm{pg} / \mathrm{ml}$ respectively). Weight loss $\geq 2.5 \%$ was associated with higher baseline BMI, weight, waist circumference, and total and visceral fat $(P<0.001$ for all). Participants with weight loss $\geq 2.5 \%$ also had a significantly higher reduction in waist circumference, FM, fat \%, VFA, and FFM than did the other groups. The participants with weight loss $\geq 2.5 \%$ also had a significantly greater improvement in both endurance and strength performance in comparison with the other groups.

\section{Correlations of changes in UAG level with weight loss, changes in body composition, and exercise}

The level of UAG correlated inversely with weight, waist circumference, FM, fat \%, and FFM at baseline (Table 3). The changes in UAG level correlated strongly and inversely with changes in weight, waist circumference, FM, and fat \%, but not with FFM. The level of UAG did not correlate with exercise performance at baseline. The change in the level of UAG correlated with the change in MFI, but not in the 12 min running test.

\section{Independent contribution of changes in the level of UAG to body fat distribution}

Multiple linear regression analysis showed that an inverse association of the level of UAG with changes in waist circumference and fat \% remained statistically significant after the adjustment for weight at baseline, weight change, and change in MFI (Table 4). The association with the change in waist circumference after the adjustments was significantly greater than the association with the fat $\%$.

\section{Discussion}

In our study of 552 young healthy Finnish men, an intensive 6-month exercise program during military service was associated with a significant increase in the level of UAG, which was associated with weight loss and reduction in surrogate markers of central and total adiposity. Our results showed that the relationship of 
Table 2 Unacylated ghrelin levels, body composition, and exercise parameters at baseline and their changes during the 6-month follow-up by the groups of weight change. Values are mean and S.D., except for baseline unacylated ghrelin values (given as median (interquartile range)).

\begin{tabular}{|c|c|c|c|c|}
\hline Variables & $\Delta$ Weight loss $\geq 2.50 \%$ & Stable weight & $\Delta$ Weight gain $\geq 2.50 \%$ & $P$ value \\
\hline \multicolumn{5}{|l|}{ Baseline } \\
\hline Unacylated ghrelin (pg/ml) & $28.6(7.8-54.4)$ & $33.9(13.7-66.2)$ & 38.6 (18.6-82.7) & 0.001 \\
\hline Body mass index & $27.7(4.3)$ & $23.1(2.8)$ & $21.2(2.5)$ & $<0.001$ \\
\hline Weight (kg) & $86.2(15.4)$ & 71.7 (9.6) & $65.2(8.4)$ & $<0.001$ \\
\hline Waist circumference $(\mathrm{cm})$ & $90.8(11.5)$ & $79.4(6.4)$ & $74.4(6.4)$ & $<0.001$ \\
\hline Fat mass $(\mathrm{kg})$ & $22.2(10.5)$ & $11.6(5.5)$ & $7.4(4.2)$ & $<0.001$ \\
\hline Fat $\%$ & $24.7(7.9)$ & $15.7(5.6)$ & $11.1(5.0)$ & $<0.001$ \\
\hline Fat-free mass $(\mathrm{kg})$ & $64.0(7.6)$ & $60.1(6.4)$ & $57.8(6.5)$ & $<0.001$ \\
\hline Visceral fat area $\left(\mathrm{cm}^{2}\right)$ & $112.6(54.2)$ & $57.2(37.2)$ & $37.1(27.0)$ & $<0.001$ \\
\hline 12 min running test $(\mathrm{m})$ & $2189(326)$ & $2420(511)^{\prime}$ & $2563(327)$ & $<0.001$ \\
\hline Muscle fitness index (points) & $5.4(3.4)$ & $8.0(3.5)$ & $8.7(3.8)$ & $<0.001$ \\
\hline \multicolumn{5}{|l|}{ Change during the follow-up } \\
\hline Unacylated ghrelin $(\mathrm{pg} / \mathrm{ml})$ & $19.1(40.5)$ & $13.6(43.9)$ & $2.9(48.2)$ & 0.005 \\
\hline Weight $(\mathrm{kg})$ & $-7.2(4.2)$ & $0.0(1.1)$ & $4.2(1.8)$ & $<0.001$ \\
\hline Waist circumference $(\mathrm{cm})$ & $-6.2(5.4)$ & 0.7 (3.3) & $4.5(3.7)$ & $<0.001$ \\
\hline Fat mass $(\mathrm{kg})$ & $-6.7(4.6)$ & $-0.9(2.0)$ & $2.0(1.8)$ & $<0.001$ \\
\hline Fat $\%$ & $-5.9(3.8)$ & $-1.1(2.6)$ & $2.3(2.6)$ & $<0.001$ \\
\hline Fat-free mass $(\mathrm{kg})$ & $-0.50(2.4)$ & $1.0(1.8)$ & $2.2(2.0)$ & $<0.001$ \\
\hline Visceral fat area $\left(\mathrm{cm}^{2}\right)$ & $-60.1(32.6)$ & $-26.7(22.4)$ & $-13.9(20.4)$ & $<0.001$ \\
\hline 12 min running test $(\mathrm{m})$ & $311(276)$ & $214(454)$ & $150(274)$ & $<0.001$ \\
\hline Muscle fitness index (points) & $2.1(2.2)$ & $1.2(2.5)$ & $1.0(2.4)$ & $<0.001$ \\
\hline
\end{tabular}

$P$ value is for ANOVA. $P$ values for differences at baseline are for log transformed where appropriate.

UAG with central obesity was stronger than with total FM, suggesting an association with the distribution of fat. Furthermore, UAG was associated with the distribution of fat independent of weight at baseline, weight loss, and improvement in exercise performance. Thus, our results provide novel evidence for the association of UAG with changes in adiposity and body composition in response to exercise.

Previous intervention studies have reported increases in total ghrelin levels after diet-induced weight loss in adults in some $(19,20)$, but not in all, studies $(21)$, and in children (22). Kim et al. (13) reported a strong inverse correlation of a change in UAG level, but not in AG level, with changes in body weight and BMI during a 3-month exercise intervention in 17 overweight children. Our findings are in agreement with Kim et al. (13), showing a strong inverse correlation of a change in the UAG level with weight change during a long-term exercise intervention in 522 young men.

In our study, we observed an increase in the level of UAG during a 6-month exercise intervention. Importantly, the increase in the level of UAG was pronounced among those with the greatest reduction in total and visceral fat, and among those with weight loss $\geq 2.5 \%$. Our findings of an increased level of UAG associated with an exercise intervention are in agreement with previous reports of total ghrelin $(10,11)$.

A regulatory role of UAG on adipogenesis has been reported in animal studies $(3,23)$. Zhang et al. (23) reported a reduction in white adipose tissue and resistance to high-fat diet-induced obesity with an increase in plasma UAG concentrations in transgenic fatty acid-binding protein 4 mice. In contrast,
Thompson et al. (3) observed parallel adipogenic effects of UAG with AG, via a mechanism independent of the $\mathrm{GHS}_{1 \mathrm{a}}$ in rats. Davies et al. (24) observed that a chronic infusion of AG induced abdominal obesity, whereas UAG had no effect on adiposity in rats.

In humans, an inverse association of both UAG and total ghrelin and FM has been reported in children during lifestyle intervention $(9,22)$. Central adiposity has been associated with total ghrelin, but not with UAG $(9,22)$, possibly due to a small sample size. Our results show that the association of change in UAG level with the change in total and abdominal fat is independent of weight at baseline, weight change, and also improvement in exercise performance.

Table 3 Correlations between the level of unacylated ghrelin, body composition, and exercise performance at baseline and the changes during the 6-month follow-up. Correlations are Spearman correlations.

\begin{tabular}{|c|c|c|c|c|}
\hline \multirow[b]{2}{*}{ Variable } & \multicolumn{2}{|c|}{$\begin{array}{c}\text { Baseline } \\
\text { measurements }\end{array}$} & \multicolumn{2}{|c|}{$\begin{array}{c}\text { Change during } \\
\text { 6-month } \\
\text { follow-up }\end{array}$} \\
\hline & $r$ & $P$ value & $r$ & $P$ value \\
\hline Weight (kg) & -0.192 & $<0.001$ & -0.130 & 0.005 \\
\hline Waist circumference $(\mathrm{cm})$ & -0.244 & $<0.001$ & -0.224 & $<0.001$ \\
\hline Waist-hip ratio & -0.084 & 0.062 & 0.015 & 0.742 \\
\hline Fat mass (kg) & -0.176 & $<0.001$ & -0.164 & $<0.001$ \\
\hline Body fat $(\%)$ & -0.166 & $<0.001$ & -0.164 & $<0.001$ \\
\hline Visceral fat area $\left(\mathrm{cm}^{2}\right)$ & 0.007 & 0.881 & 0.043 & 0.358 \\
\hline Fat-free mass $(\mathrm{kg})$ & -0.129 & 0.004 & 0.012 & 0.791 \\
\hline 12 min running test $(\mathrm{m})$ & 0.006 & 0.900 & 0.020 & 0.663 \\
\hline $\begin{array}{l}\text { Muscle fitness index } \\
\text { (points) }\end{array}$ & 0.062 & 0.176 & 0.113 & 0.013 \\
\hline
\end{tabular}


Table 4 Associations of a change $(\Delta)$ in the level of unacylated ghrelin (UAG) with changes $(\Delta)$ in waist circumference and fat percentage. Values are standardized beta $(\beta)$, effect size (B), and S.E.M.

\begin{tabular}{|c|c|c|c|c|c|c|c|c|}
\hline & \multicolumn{4}{|c|}{$\Delta$ Waist circumference } & \multicolumn{4}{|c|}{$\Delta$ Fat $\%$} \\
\hline & $\beta$ & $\mathrm{B}$ & S.E.M. & $P$ value & $\beta$ & $\mathrm{B}$ & S.E.M. & $P$ value \\
\hline $\begin{array}{l}\text { Model } 1 \\
\text { Model } 2 \\
\text { Model } 3 \\
\text { Model } 4 \\
\text { Model } 5\end{array}$ & $\begin{array}{l}-0.210 \\
-0.142 \\
-0.105 \\
-0.133 \\
-0.109\end{array}$ & $\begin{array}{l}-0.029 \\
-0.019 \\
-0.015 \\
-0.017 \\
-0.014\end{array}$ & $\begin{array}{l}0.006 \\
0.005 \\
0.003 \\
0.005 \\
0.003\end{array}$ & $\begin{array}{l}2.6 \times 10^{-6} \\
1.7 \times 10^{-4} \\
4.3 \times 10^{-5} \\
1.6 \times 10^{-3} \\
9.4 \times 10^{-5}\end{array}$ & $\begin{array}{l}-0.166 \\
-0.081 \\
-0.053 \\
-0.073 \\
-0.057\end{array}$ & $\begin{array}{l}-0.017 \\
-0.008 \\
-0.005 \\
-0.007 \\
-0.006\end{array}$ & $\begin{array}{l}0.005 \\
0.004 \\
0.003 \\
0.004 \\
0.003\end{array}$ & $\begin{array}{l}3.0 \times 10^{-4} \\
0.029 \\
0.045 \\
0.052 \\
0.038\end{array}$ \\
\hline
\end{tabular}

Model 1, association of $\Delta$ UAG with $\Delta$ waist and $\Delta$ fat $\%$; model 2 , association of $\Delta$ UAG with $\Delta$ waist and $\Delta$ fat $\%$ adjusted for weight at baseline); model 3 , association of $\Delta U A G$ with $\Delta$ waist and $\Delta$ fat $\%$ adjusted for weight at baseline and $\Delta$ weight; model 4 , association of $\Delta U A G$ with $\Delta$ waist and $\Delta$ fat $\%$ adjusted for weight at baseline and $\Delta$ muscle fitness index (MFI); model 5 , association of $\Delta$ UAG with $\Delta$ waist and $\Delta$ fat $\%$ adjusted for weight at baseline, $\Delta$ weight, and $\Delta$ MFI. Univariate regression analysis was used for model 1 and multivariate linear regression analysis for models $2-5$.

It is important to note that our study demonstrates a stronger association between the change in the level of UAG and central obesity than with total FM. Large amounts of visceral fat predicts mortality (25), and it is strongly associated with elevated blood pressure, low high-density lipoprotein (HDL)/total cholesterol ratio, and insulin resistance (26). Moreover, visceral fat is associated with qualitative and quantitative changes in lipids and lipoproteins, such as increases in total cholesterol, very low-density lipoproteins (VLDL), small dense LDL particles, triglycerides, and decreases in HDL cholesterol levels (27). Thus, a reduction in visceral fat plays a key role in the improvement of cardiometabolic risk factor profile associated with weight loss and exercise (14).

The association of the orexigenic properties of UAG with other functions of UAG remains uncertain. AG, but not UAG, has been reported to stimulate food intake in rodents (7). Asakawa et al. (28) have reported an inverse effect of UAG to AG on food intake, with decreased food intake and delayed gastric emptying induced by UAG in mice. The orexigenic properties of UAG in humans remain uncertain. Further studies are needed to ascertain whether the association of high levels of UAG with weight loss and reduction in FM reflect the effect of UAG on appetite. Our study was carried out in the military setting and did not include dietary intervention. The participants did not have reduced calorie intake, with the intended content of energy in the food served to every conscript by the military forces being 3200-3600 kcal/day, of which $30-35 \%$ consist of fat (29). Dietary lipids may in fact play an important role in ghrelin acylation, and the ghrelin $\mathrm{O}$-acyl transferase has been suggested to provide a link between ingested lipids, energy expenditure and body composition (30).

To our knowledge, our study is the first longitudinal study evaluating exercise-associated changes in the level of UAG with changes to body composition in adults and the association of UAG with body fat distribution. Exercise performance was objectively measured using standardized tests, and the cohort was a large representative sample of young healthy men, with standardized meals and living circumstances. However, our study has limitations. We did not have a control group due to the study design, although each of the participants served as their own controls. VFA was evaluated by InBody 720 (BIA), and more studies are needed to validate this method in different ethnic groups. The training protocol and diet are somewhat different compared with other non-military cohorts. Inevitable changes in diet and environment associated with military service may have had some effect on body weight. Our results are also limited to young healthy men and must be generalized to other populations with caution.

In conclusion, our study including 552 young men demonstrated an increase in UAG level during an intensive 6-month exercise program that was associated with weight loss and reduction in total and central FM. The change in the level of UAG was associated with total and central FM independently of weight at baseline, weight change, and change in exercise performance. The change in the level of UAG was associated with the distribution of body fat, independent of weight at baseline, weight change, and change in exercise performance.

\section{Declaration of interest}

The authors declare that there is no conflict of interest that could be perceived as prejudicing the impartiality of the research reported.

\section{Funding}

The study was supported by the EVO state funding for health sciences research from the North Ostrobotnia Hospital District, Finland.

\section{Acknowledgements}

The authors thank Dr Mauri Laakso, Dr Ilona Mikkola, Dr Anna-Kaisa Juuti, Mrs Pirjo Härkönen, Mr Eero Saastamoinen, Medical Colonel Dr Ari Peitso, and all the staff involved in the data collection for their assistance with the study.

\section{References}

1 Kojima M, Hosoda H, Date Y, Nakazato M, Matsuo H \& Kangawa K. Ghrelin is a growth-hormone-releasing acylated peptide from stomach. Nature 1999402 656-660. (doi:10.1038/45230) 
2 Ukkola O. Ghrelin and metabolic disorders. Current Protein and Peptide Science 200910 2-7. (doi:10.2174/138920309787315220)

3 Thompson NM, Gill DA, Davies R, Loveridge N, Houston PA, Robinson IC \& Wells T. Ghrelin and des-octanoyl ghrelin promote adipogenesis directly in vivo by a mechanism independent of the type la growth hormone secretagogue receptor. Endocrinology 2004145 234-242. (doi:10.1210/en.2003-0899)

4 Broglio F, Gottero C, Prodam F, Gauna C, Muccioli G, Papotti M, Abribat T, van der Lely AJ \& Ghigo E. Non-acylated ghrelin counteracts the metabolic but not the neuroendocrine response to acylated ghrelin in humans. Journal of Clinical Endocrinology and Metabolism 200489 3062-3065. (doi:10.1210/jc.2003-031964)

5 Gauna C, Meyler FM, Janssen JA, Delhanty PJ, Abribat T, van Koetsveld P, Hofland LJ, Broglio F, Ghigo E \& van der Lely AJ. Administration of acylated ghrelin reduces insulin sensitivity, whereas the combination of acylated plus unacylated ghrelin strongly improves insulin sensitivity. Journal of Clinical Endocrinology and Metabolism 200489 5035-5042. (doi:10.1210/jc.2004-0363)

6 Gauna C, Delhanty PJ, Hofland LJ, Janssen JA, Broglio F, Ross RJ, Ghigo E \& van der Lely AJ. Ghrelin stimulates, whereas desoctanoyl ghrelin inhibits, glucose output by primary hepatocytes. Journal of Clinical Endocrinology and Metabolism 200590 1055-1060. (doi:10.1210/jc.2004-1069)

7 Neary NM, Druce MR, Small CJ \& Bloom SR. Acylated ghrelin stimulates food intake in the fed and fasted states but desacylated ghrelin has no effect. Gut $2006 \mathbf{5 5} 135$.

8 St-Pierre DH, Karelis AD, Coderre L, Malita F, Fontaine J, Mignault D, Brochu M, Bastard JP, Cianflone K, Doucet E, Imbeault P \& Rabasa-Lhoret R. Association of acylated and nonacylated ghrelin with insulin sensitivity in overweight and obese postmenopausal women. Journal of Clinical Endocrinology and Metabolism 200792 264-269. (doi:10.1210/jc.2006-1603)

9 Kim HJ, Lee S, Kim TW, Kim HH, Jeon TY, Yoon YS, Oh SW, Kwak H \& Lee JG. Effects of exercise-induced weight loss on acylated and unacylated ghrelin in overweight children. Clinical Endocrinology 200868 416-422. (doi:10.1111/j.1365-2265.2007.03058.x)

10 Foster-Schubert KE, McTiernan A, Frayo RS, Schwartz RS, Rajan KB, Yasui Y, Tworoger SS \& Cummings DE. Human plasma ghrelin levels increase during a one-year exercise program. Journal of Clinical Endocrinology and Metabolism 200590 820-825. (doi:10.1210/jc.2004-2081)

11 Leidy HJ, Gardner JK, Frye BR, Snook ML, Schuchert MK, Richard EL \& Williams NI. Circulating ghrelin is sensitive to changes in body weight during a diet and exercise program in normal-weight young women. Journal of Clinical Endocrinology and Metabolism $2004 \mathbf{8 9}$ 2659-2664. (doi:10.1210/jc.2003-031471)

12 Morpurgo PS, Resnik M, Agosti F, Cappiello V, Sartorio A \& Spada A. Ghrelin secretion in severely obese subjects before and after a 3-week integrated body mass reduction program. Journal of Endocrinological Investigation 200326 723-727.

13 Ravussin E, Tschop M, Morales S, Bouchard C \& Heiman ML. Plasma ghrelin concentration and energy balance: overfeeding and negative energy balance studies in twins. Journal of Clinical Endocrinology and Metabolism 200186 4547-4551. (doi:10. $1210 /$ jc. 86.9.4547)

14 Cederberg H, Mikkola I, Jokelainen J, Laakso M, Härkönen P, Ikäheimo T, Laakso M \& Keinänen-Kiukaanniemi S. Exercise during military training improves cardiovascular risk factors in young men. Atherosclerosis 2011216 489-495. (doi:10.1016/j. atherosclerosis.2011.02.037)

15 Cooper KH. A means of assessing maximal oxygen intake. Correlation between field and treadmill testing. Journal of the American Medical Association 1968203 201-204. (doi:10.1001/ jama.203.3.201)

16 Grant S, Corbett K, Amjad AM, Wilson J \& Aitchison T. A comparison of methods of predicting maximum oxygen uptake. British Journal of Sports Medicine 199529 147-152. (doi:10. 1136/bjsm.29.3.147)

17 Santtila M, Kyrolainen H, Vasankari T, Tiainen S, Palvalin K, Hakkinen A \& Hakkinen K. Physical fitness profiles in young
Finnish men during the years 1975-2004. Medicine and Science in Sports and Exercise 200638 1990-1994. (doi:10.1249/01.mss. $0000232023.28984 .78)$

18 Saaristo T, Moilanen L, Korpi-Hyovalti E, Vanhala M, Saltevo J, Niskanen L, Jokelainen J, Peltonen M, Oksa H, Tuomilehto J, Uusitupa M \& Keinanen-Kiukaanniemi S. Lifestyle intervention for prevention of type 2 diabetes in primary health care: one-year follow-up of the Finnish National Diabetes Prevention Program (FIN-D2D). Diabetes Care 201033 2146-2151. (doi:10.2337/ dc10-0410)

19 Weigle DS, Cummings DE, Newby PD, Breen PA, Frayo RS, Matthys CC, Callahan HS \& Purnell JQ. Roles of leptin and ghrelin in the loss of body weight caused by a low fat, high carbohydrate diet. Journal of Clinical Endocrinology and Metabolism $2003 \mathbf{8 8}$ 1577-1586. (doi:10.1210/jc.2002-021262)

20 Romon M, Gomila S, Hincker P, Soudan B \& Dallongeville J. Influence of weight loss on plasma ghrelin responses to high-fat and high-carbohydrate test meals in obese women. Journal of Clinical Endocrinology and Metabolism 200691 1034-1041. (doi:10.1210/jc.2005-1050)

21 Bennett NR, Boyne MS, Cooper RS, Royal-Thomas TY, Bennett FI, Luke A, Wilks RJ \& Forrester TE. Impact of adiponectin and ghrelin on incident glucose intolerance and on weight change. Clinical Endocrinology 200970 408-414. (doi:10.1111/j.1365-2265. 2008.03344.x)

22 Kelishadi R, Hashemipour M, Mohammadifard N, Alikhassy H \& Adeli K. Short- and long-term relationships of serum ghrelin with changes in body composition and the metabolic syndrome in prepubescent obese children following two different weight loss programmes. Clinical Endocrinology 200869 721-729. (doi:10. $1111 /$ j.1365-2265.2008.03220.x)

23 Zhang W, Chai B, Li JY, Wang H \& Mulholland MW. Effect of desacyl ghrelin on adiposity and glucose metabolism. Endocrinology 2008149 4710-4716. (doi:10.1210/en.2008-0263)

24 Davies JS, Kotokorpi P, Eccles SR, Barnes SK, Tokarczuk PF, Allen SK, Whitworth HS, Guschina IA, Evans BA, Mode A, Zigman JM \& Wells T. Ghrelin induces abdominal obesity via GHSR-dependent lipid retention. Molecular Endocrinology 200923 914-924. (doi:10.1210/me.2008-0432)

25 Kuk JL, Katzmarzyk PT, Nichaman MZ, Church TS, Blair SN \& Ross R. Visceral fat is an independent predictor of all-cause mortality in men. Obesity 200614 336-341. (doi:10.1038/oby.2006.43)

26 Nieves DJ, Cnop M, Retzlaff B, Walden CE, Brunzell JD, Knopp RH \& Kahn SE. The atherogenic lipoprotein profile associated with obesity and insulin resistance is largely attributable to intraabdominal fat. Diabetes $2003 \mathbf{5 2}$ 172-179. (doi:10.2337/ diabetes.52.1.172)

27 Howard BV, Ruotolo G \& Robbins DC. Obesity and dyslipidemia. Endocrinology and Metabolism Clinics of North America 200332 855-867. (doi:10.1016/S0889-8529(03)00073-2)

28 Asakawa A, Inui A, Fujimiya M, Sakamaki R, Shinfuku N, Ueta Y, Meguid MM \& Kasuga M. Stomach regulates energy balance via acylated ghrelin and desacyl ghrelin. Gut 2005 54 18-24. (doi:10.1136/gut.2004.038737)

29 Tähtinen T, Vanhala M, Oikarinen J \& Keinänen-Kiukaanniemi S. Changes in insulin resistance-associated cardiovascular risk factors of Finnish men during military service. Annales Medicinae Militaris Fenniae 200075 163-170.

30 Kirchner H, Gutierrez JA, Solenberg PJ, Pfluger PT, Czyzyk TA, Willency JA, Schurmann A, Joost HG, Jandacek RJ, Hale JE, Heiman ML \& Tschop MH. GOAT links dietary lipids with the endocrine control of energy balance. Nature Medicine 200915 741-745. (doi:10.1038/nm.1997)

Received 14 April 2011

Accepted 6 June 2011 